\title{
Current neurosurgical management of glossopharyngeal neuralgia and technical nuances for microvascular decompression surgery
}

\author{
Roberto Rey-Dios, M.D., ${ }^{1}$ and Aaron A. Cohen-Gadol, M.D., M.Sc. ${ }^{2}$ \\ ${ }^{1}$ Department of Neurosurgery, University of Mississippi Medical Center, Jackson, Mississippi; ${ }^{2}$ Goodman \\ Campbell Brain and Spine, Indiana University Department of Neurological Surgery, Indianapolis, Indiana
}

\begin{abstract}
Glossopharyngeal neuralgia (GPN) is an uncommon facial pain syndrome often misdiagnosed as trigeminal neuralgia. The rarity of this condition and its overlap with other cranial nerve hyperactivity syndromes often leads to a significant delay in diagnosis. The surgical procedures with the highest rates of pain relief for GPN are rhizotomy and microvascular decompression (MVD) of cranial nerves IX and X. Neurovascular conflict at the level of the root exit zone of these cranial nerves is believed to be the cause of this pain syndrome in most cases. Vagus nerve rhizotomy is usually reserved for cases in which vascular conflict is not evident. A review of the literature reveals that although the addition of cranial nerve $\mathrm{X}$ rhizotomy may improve the chances of long-term pain control, this maneuver also increases the risk of permanent dysphagia and vocal cord paralysis. The risks of this procedure have to be carefully weighed against its benefits. Based on the authors' experience, careful patient selection with a thorough exploratory operation most often leads to identification of the site of vascular conflict, obviating the need for cranial nerve $\mathrm{X}$ rhizotomy.

(http://thejns.org/doi/abs/10.3171/2012.12.FOCUS12391)
\end{abstract}

$\begin{array}{lll}\text { KEY WORDS } & \text { glossopharyngeal neuralgia } \bullet \\ \text { vagus nerve } & \bullet & \text { rhizotomy }\end{array}$

microvascular decompression •

$\mathrm{G}^{\mathrm{s}}$ LOSSOPHARYNGEAL neuralgia, or vagoglossopharyngeal neuralgia, is a cranial nerve hyperactivity pain syndrome leading to severe, transient, sharp pain in the ear, base of the tongue, tonsillar fossa, or beneath the angle of the jaw corresponding to the distributions of the auricular and pharyngeal branches of cranial nerves IX and X. Swallowing, chewing, talking, coughing, or yawning commonly trigger this pain. These painful attacks are neuralgic and therefore paroxysmal, lasting for less than a second and as long as a few minutes. Recently the International Headache Society proposed a subclassification of GPN that includes classic and symptomatic forms. In the classic type, the pain is only intermittent with no underlying cause or associated neurological deficit. The symptomatic type includes the same characteristics of the classic form; however, the aching pain can persist between neuralgic episodes, and sensory

\footnotetext{
Abbreviations used in this paper: GPN = glossopharyngeal neuralgia; $\mathrm{MVD}=$ microvascular decompression; $\mathrm{TN}=$ trigeminal neuralgia.
}

impairment can be found in the distribution of the above nerves due to structural lesions..$^{20}$ This classification does not take into consideration associated syncopal events. Neoplastic processes causing symptomatic GPN are usually malignant and tend to affect the nerve at its extracranial segment, in contrast to TN caused by benign tumors in the cerebellopontine angle in 5\%-8\% of cases. ${ }^{4}$

Infectious and inflammatory processes may also lead to GPN. Multiple sclerosis is rarely the cause of GPN, but is the cause in as many as $3 \%$ of cases of TN. ${ }^{4}$ The pain syndrome of GPN can be very similar to that of TN, leading to a misdiagnosis if a thorough history is not obtained. The tracts of trigeminal, glossopharyngeal, and vagus nerves have an intimal neuroanatomical and functional relationship, and overlapping symptoms are not uncommon. ${ }^{33,38,50,65,71}$ However, GPN and TN do not usually occur simultaneously. ${ }^{6}$

Glossopharyngeal neuralgia is a rare entity, representing only $0.2 \%-1.3 \%$ of facial pain syndromes. ${ }^{8,16}$ The overall incidence of GPN in the population is estimated to be between 0.2 and 0.7 per 100,000 people per 


\section{R. Rey-Dios and A. A. Cohen-Gadol}

year. $29,36,44,54$ This incidence is probably underestimated due to insufficient awareness of this condition. Glossopharyngeal neuralgia is more common on the left side (left:right ratio of 3:2), but $\mathrm{TN}$ is more common on the right (right:left ratio 5:3). ${ }^{29}$ Bilateral involvement (usually sequentially and not simultaneously) is more common in TN (4\%) than in GPN (2\%). ${ }^{4}$ Glossopharyngeal neuralgia can lead to bradycardia and loss of sympathetic tone, and therefore syncopal episodes and even seizures occur in as many as $10 \%$ of the cases. ${ }^{1,3,12,14,35,58,63,68}$ In rare cases GPN can present as syncope with no associated pain syndrome ${ }^{49}$ making the diagnosis even more difficult. Like TN, GPN is treated using anticonvulsant medications, but this latter condition tends to be more refractory to medical therapy, especially in patients with vascular compression. ${ }^{11,13,32,37,42,51,53,64}$ Pain refractory to medical therapy and poor tolerance of drug side effects are common indications for surgical intervention.

\section{Historical Perspectives}

Extracranial nerve ablation was one of the first procedures attempted for treatment of GPN. ${ }^{43,57}$ This approach was abandoned due to its high morbidity and pain recurrence due to a lack of supraganglionic ablation. Dandy ${ }^{10}$ performed some of the first intracranial rhizotomies of the glossopharyngeal nerve with good results. Even though short-term results were good after these procedures, longterm pain recurrence was frequent. Rhizotomy of the vagus sensory rootlets improved long-term outcomes., ${ }^{5,41}$ Intracranial rhizotomies of cranial nerves IX and X were the preferred surgical procedure until the 1970s. Based on his intraoperative observations, Dandy ${ }^{9}$ proposed vascular compression of the root entry/exit zones of the cranial nerves as a possible cause for cranial nerve hyperactivity syndromes. Jannetta ${ }^{22-25}$ further investigated this mechanism and published the first series of patients with GPN treated with MVD. ${ }^{39}$ Since that time, this operation has gained greater acceptance than the traditional rhizotomy procedures and many series have been published regarding its efficacy. ${ }^{15-17,26,30,34,39,45-47,50,56,60,67}$

Percutaneous procedures have been devised as an alternative to craniotomy; these procedures include radiofrequency rhizotomy ${ }^{2,4,12,18,21,40,55}$ and trigeminal tractotomy. ${ }^{27,28,38}$ Most recently, stereotactic radiosurgery has also been explored. ${ }^{48,59,70}$

Although cranial nerve IX rhizotomy is low risk ${ }^{66}$ and has been advocated during MVD for GPN, ${ }^{69}$ the efficacy of cranial nerve $\mathrm{X}$ rhizotomy, when considering the associated risks, remains less defined. We therefore attempted a comprehensive review of the literature to explore the role of cranial nerve $\mathrm{X}$ rhizotomy in a large group of patients. In addition, the senior author (A.A.C.G.) will describe his early personal experience and lessons learned from 15 such procedures.

\section{Literature Search}

We conducted a literature search to evaluate the impact of sectioning the upper rootlets of cranial nerve $\mathrm{X}$ on overall postoperative pain control and morbidity as com- pared with MVD of cranial nerve $\mathrm{X}$ alone. Our literature search (using search terms such as "glossopharyngeal neuralgia" along with "microvascular decompression" or "rhizotomy") yielded 11 reports of MVD alone (427 patients), 3 series that included both procedures (38 patients), and 4 that included rhizotomy alone (146 patients). Overall, we found 454 patients who underwent MVD and 157 who underwent rhizotomy of the upper rootlets of cranial nerve $\mathrm{X}$ (Tables 1 and 2).

\section{Results}

The mean age of the patients in both series at the time of surgery was 54.5 years. Of these patients, $57.3 \%$ were female and $65 \%$ presented with left-sided pain. Only 5 patients $(0.8 \%)$ were reported to have bilateral neuralgia. In terms of the primary location of the pain, the throat type was the most common across the series $(35.8 \%)$, followed by combined throat and ear pain (34\%). Isolated ear pain was rare and averaged only $11.3 \%$ among patients. Only 7 patients $(1.1 \%)$ presented with syncope. The mean duration of symptoms was 5.3 years. The overall reported surgical mortality rate was $2.1 \%$. The mortality rates for MVD and rhizotomy procedures were $1.1 \%$ and $5 \%$, respectively. However, these mortality rates correspond to those in the largest series available (Rushton et al. ${ }^{54}$ ), which includes patients operated on before the current microsurgery era. There was no mortality reported for the rhizotomy operation in the other 6 most recent series.

Mean follow-up duration was 4.9 years for the MVD group ( 2 series did not report follow-up time) and 4.7 years for the rhizotomy group ( 3 series, including Rushton et al., ${ }^{54}$ did not report the length of follow-up). The rate of long-term pain freedom for patients who underwent MVD was $84.7 \%$ with recurrence in $7 \%$ of patients. Pain freedom for patients who underwent rhizotomy was $87.3 \%$ with pain recurrence in $8.2 \%$. If the series from Rushton et al. ${ }^{54}$ is excluded, the rate of long-term relief after rhizotomy for more recent series is $96.4 \%$ with no long-term recurrence.

Transient cranial nerve $\mathrm{X}$ dysfunction (dysphagia, hoarseness, or both) occurred in $13.2 \%$ of MVD cases and $25 \%$ of rhizotomy cases. Permanent cranial nerve $\mathrm{X}$ deficits occurred in 5.5\% of MVD operations on average (1 group did not report on permanent deficits) and 19.1\% of rhizotomy cohorts. If the data from the era before microsurgery are excluded, the rate of permanent cranial nerve $\mathrm{X}$ dysfunction is $17.8 \%$.

\section{Discussion}

Microvascular decompression is currently the most effective operation to treat GPN. If exploratory surgery does not identify an offending vessel, sectioning cranial nerve IX and the upper rootlets of cranial nerve $\mathrm{X}$ is an option. ${ }^{66}$ However, this maneuver can lead to dysphagia and vocal cord paralysis. ${ }^{31,54}$ Monitoring the motor vagus by placing electrodes directly on the false vocal cords ${ }^{61}$ or surface electrodes on the endotracheal tube ${ }^{19}$ can help the surgeon distinguish motor from sensory roots and thus potentially decrease the morbidity of the procedure. 
Management of glossopharyngeal neuralgia

TABLE 1: Summary of studies involving MVD of the upper rootlets of cranial nerve $X$ for GPN*

\begin{tabular}{|c|c|c|c|c|c|c|c|c|c|}
\hline Authors \& Year & $\begin{array}{l}\text { No. of } \\
\text { Patients }\end{array}$ & $\begin{array}{c}\text { Mean } \\
\text { Age (yrs) }\end{array}$ & Deaths (\%) & $\begin{array}{c}\text { Mean Follow- } \\
\text { Up (yrs) }\end{array}$ & $\begin{array}{l}\text { Transient CN } \\
\text { X Deficit (\%) }\end{array}$ & $\begin{array}{c}\text { Permanent CN } \\
\text { X Deficit (\%) }\end{array}$ & $\begin{array}{c}\text { Total } \\
\text { Relief (\%) }\end{array}$ & $\begin{array}{c}\text { Partial } \\
\text { Relief (\%) }\end{array}$ & $\begin{array}{c}\text { No } \\
\text { Relief (\%) }\end{array}$ \\
\hline Laha \& Jannetta, 1977 & 3 & 44.3 & $1(33.3)$ & 0.7 & $1(50)$ & $1(50)$ & $1(50)$ & $1(50)$ & \\
\hline Jannetta, 1980 & 9 & $30-69$ & $1(11.1)$ & NR & $2(25)$ & 0 & $6(75)$ & & $2(25)$ \\
\hline Michelucci et al., 1986 & 3 & 56.9 & 0 & 1.8 & 0 & 0 & $3(100)$ & & \\
\hline Wakiya et al., 1989 & 16 & 54.7 & 0 & 2 & $6(37.5)$ & $1(6.2)$ & $15(93.7)$ & $1(6.3)$ & \\
\hline Resnick et al., 1995 & 40 & 55 & $2(5)$ & 4 & $4(10)$ & $3(8)$ & $28(76)$ & $6(15)$ & $3(8)$ \\
\hline Kondo, 1998 & 17 & 59.3 & $1(5.9)$ & 11.6 & $2(12.5)$ & $2(12.5)$ & $16(100)$ & & \\
\hline Matsushima et al., 2000 & 3 & 59.3 & 0 & 1.3 & 0 & 0 & $3(100)$ & & \\
\hline Patel et al., 2002 & 217 & 50.2 & 0 & $4 \dagger$ & $14(6.25)$ & NR & $29(58)$ & $9(18)$ & $12(24)$ \\
\hline Sampson et al., 2004 & 47 & 56.4 & 0 & $12.7 \ddagger$ & $14(27.6)$ & $4(8.5)$ & $28(96.5)$ & & $1(3.4)$ \\
\hline Ferroli et al., 2009 & 31 & 55.8 & 0 & 7.5 & $3(9.7)$ & 0 & $28(90.3)$ & $3(9.7)$ & \\
\hline Kawashima et al., 2010 & 14 & 59.2 & 0 & 6.5 & $4(28.6)$ & 0 & $20(95.2)$ & $1(4.7)$ & \\
\hline Kandan et al., 2010 & 15 & 52.5 & 0 & 4 & $4(26.7)$ & $2(13.3)$ & $14(93.3)$ & $1(6.7)$ & \\
\hline Gaul et al., 2011 & 18 & 54.5 & 0 & NR & $6(33.3)$ & 0 & $16(88.9)$ & $1(5.5)$ & $1(5.5)$ \\
\hline Xiong et al., 2012 & 21 & 50.4 & 0 & 3.4 & 0 & 0 & $21(100)$ & & \\
\hline
\end{tabular}

* $\mathrm{CN}=$ cranial nerve; $\mathrm{NR}=$ not reported.

$\dagger$ Long-term follow-up available in only 50 patients in this series.

$\ddagger$ Long-term follow-up available in only 29 patients in this series.

Sectioning the upper rootlets of cranial nerve $X$ to improve pain control is based on clinical observations rather than careful, reliable anatomical/functional studies..$^{52}$ The vagus nerve does not have a craniocaudal sensorimotor organization, and in fact, the sensory fibers might be located dorsally and the motor fibers ventrally. ${ }^{62}$ However, accumulated experience from older series (not considering MVD as an option) has demonstrated a high pain recurrence rate when cranial nerve IX and X rhizotomies are not performed simultaneously. Physiologically, sectioning the upper rootlets of the vagus nerve increases the pharyngeal sensory loss already caused by cranial nerve IX rhizotomy, potentially resulting in paralysis of the ipsilateral vocal cord and motor arc of the gag reflex. Most authors describe rhizotomy of the upper rootlets of cranial nerve $\mathrm{X}$ as benign, leading only to an irritative cough, foreign body sensation in the throat, and transient hoarseness or dysphagia. . $^{8,31,54}$

Our review of the literature disclosed a 3 -fold increase $(18 \%$ vs $6 \%)$ in the risk of permanent postoperative cranial nerve $\mathrm{X}$ dysfunction during rhizotomy versus MVD, respectively. The rate of pain control increases slightly
(85\% vs $96 \%$ ) for MVD and cranial nerve X rhizotomy, respectively. We therefore routinely avoided sectioning the upper rootlets of cranial nerve $\mathrm{X}$ in our 15 patients. In our series, all patients were found to have offending vessels without a need for cranial nerve $\mathrm{X}$ rhizotomy. We believe that careful patient selection and thorough inspection of the cranial nerve $\mathrm{X}$ root exit zone will minimize the rate of "negative" exploratory operations requiring cranial nerve $\mathrm{X}$ rhizotomy.

Our review of the literature disclosed consistent trends in reporting postoperative results. The number of patients in the reported series is most often small. The reporting paradigms are too heterogeneous and often do not include adequate information to draw meaningful conclusions. However, it appears that rhizotomy leads to slightly better pain control at the expense of higher postoperative permanent cranial nerve dysfunction. Based on our experience, careful patient selection with a through and safe exploratory operation most often leads to identification of the site of vascular compression, obviating the need for cranial nerve $\mathrm{X}$ rhizotomy, which is associated with a higher rate of cranial nerve dysfunction.

TABLE 2: Summary of studies involving rhizotomy of the upper rootlets of cranial nerve $X$ for GPN

\begin{tabular}{|c|c|c|c|c|c|c|c|c|c|}
\hline Authors \& Year & $\begin{array}{c}\text { No. of } \\
\text { Patients }\end{array}$ & $\begin{array}{c}\text { Mean Age } \\
\text { (yrs) }\end{array}$ & Deaths & $\begin{array}{c}\text { Mean Follow- } \\
\text { Up (yrs) }\end{array}$ & $\begin{array}{l}\text { Transient CN } \\
\text { X Deficit (\%) }\end{array}$ & $\begin{array}{c}\text { Permanent CN } \\
\text { X Deficit (\%) }\end{array}$ & $\begin{array}{c}\text { Total } \\
\text { Relief (\%) }\end{array}$ & $\begin{array}{c}\text { Partial } \\
\text { Relief (\%) }\end{array}$ & $\begin{array}{c}\text { No } \\
\text { Relief (\%) }\end{array}$ \\
\hline Laha \& Jannetta, 1977 & 3 & 59.3 & 0 & 3 & $1(33.3)$ & $1(33.3)$ & $3(100)$ & & \\
\hline Jannetta, 1980 & 2 & $30-69$ & 0 & NR & 0 & $2(100)$ & $2(100)$ & & \\
\hline Rushton et al., 1981 & 129 & NR & $7(5 \%)$ & NR & NR & $25(19.4)$ & $110(85.3)$ & & $13(10)$ \\
\hline Fraioli et al., 1989 & 3 & 62.3 & 0 & NR & $1(33.3)$ & 0 & $3(100)$ & & \\
\hline Taha \& Tew, 1995 & 12 & 42.7 & 0 & 10 & $2(16.7)$ & $2(16.7)$ & $12(100)$ & & \\
\hline Ceylan et al., 1997 & 2 & 55.5 & 0 & 2 & $2(100)$ & 0 & $2(100)$ & & \\
\hline Kandan et al., 2010 & 6 & 52.5 & 0 & 4 & $1(16.7)$ & 0 & $5(83.3)$ & $1(16.7)$ & \\
\hline
\end{tabular}




\section{R. Rey-Dios and A. A. Cohen-Gadol}

\section{Disclosure}

The authors report no conflict of interest concerning the materials or methods used in this study or the findings specified in this paper.

Author contributions to the study and manuscript preparation include the following. Conception and design: both authors. Acquisition of data: both authors. Analysis and interpretation of data: both authors. Drafting the article: both authors. Critically revising the article: both authors. Reviewed submitted version of manuscript: both authors.

\section{References}

1. Acosta C, Clark K: Glossopharyngeal neuralgia associated with cardiac arrest. Case report. J Neurosurg 32:706-707, 1970

2. Arbit E, Krol G: Percutaneous radiofrequency neurolysis guided by computed tomography for the treatment of glossopharyngeal neuralgia. Neurosurgery 29:580-582, 1991

3. Barbash GI, Keren G, Korczyn AD, Sharpless NS, Chayen M, Copperman Y, et al: Mechanisms of syncope in glossopharyngeal neuralgia. Electroencephalogr Clin Neurophysiol 63: 231-235, 1986

4. Barrow DL (ed): Surgery of the Cranial Nerves of the Posterior Fossa. New York: Thieme, 1993

5. Bohm E, Strang RR: Glossopharyngeal neuralgia. Brain 85: 371-388, 1962

6. Bruyn GW: Glossopharyngeal neuralgia. Cephalalgia 3:143157,1983

7. Ceylan S, Karakuş A, Duru S, Baykal S, Koca O: Glossopharyngeal neuralgia: a study of 6 cases. Neurosurg Rev 20: 196-200, 1997

8. Chawla JC, Falconer MA: Glossopharyngeal and vagal neuralgia. BMJ 3:529-531, 1967

9. Dandy WE: Concerning the cause of trigeminal neuralgia. Am J Surg 24:447-455, 1934

10. Dandy WE: Glossopharyngeal neuralgia (tic doloreaux). Its diagnosis and treatment. Arch Surg 15:198-214, 1927

11. De Simone R, Ranieri A, Bilo L, Fiorillo C, Bonavita V: Cranial neuralgias: from physiopathology to pharmacological treatment. Neurol Sci 29 (Suppl 1):S69-S78, 2008

12. Esaki T, Osada H, Nakao Y, Yamamoto T, Maeda M, Miyazaki T, et al: Surgical management for glossopharyngeal neuralgia associated with cardiac syncope: two case reports. Br J Neurosurg 21:599-602, 2007

13. Evans RW, Torelli P, Manzoni GC: Glossopharyngeal neuralgia. Headache 46:1200-1202, 2006

14. Ferrante L, Artico M, Nardacci B, Fraioli B, Cosentino F, Fortuna A: Glossopharyngeal neuralgia with cardiac syncope. Neurosurgery 36:58-63, 1995

15. Ferroli P, Fioravanti A, Schiariti M, Tringali G, Franzini A, Calbucci F, et al: Microvascular decompression for glossopharyngeal neuralgia: a long-term retrospectic review of the Milan-Bologna experience in 31 consecutive cases. Acta Neurochir (Wien) 151:1245-1250, 2009

16. Fraioli B, Esposito V, Ferrante L, Trubiani L, Lunardi P: Microsurgical treatment of glossopharyngeal neuralgia: case reports. Neurosurgery 25:630-632, 1989

17. Gaul C, Hastreiter P, Duncker A, Naraghi R: Diagnosis and neurosurgical treatment of glossopharyngeal neuralgia: clinical findings and 3-D visualization of neurovascular compression in 19 consecutive patients. J Headache Pain 12:527-534, 2011

18. Giorgi C, Broggi G: Surgical treatment of glossopharyngeal neuralgia and pain from cancer of the nasopharynx. A 20 -year experience. J Neurosurg 61:952-955, 1984

19. Harries AM, Dong CCJ, Honey CR: Use of endotracheal tube electrodes in treating glossopharyngeal neuralgia: technical note. Stereotact Funct Neurosurg 90:141-144, 2012
20. Headache Classification Subcommittee of the International Headache Society: The International Classification of Headache Disorders: 2nd edition. Cephalalgia 24 Suppl 1:9-160, 2004

21. Isamat F, Ferrán E, Acebes JJ: Selective percutaneous thermocoagulation rhizotomy in essential glossopharyngeal neuralgia. J Neurosurg 55:575-580, 1981

22. Jannetta PJ: Arterial compression of the trigeminal nerve at the pons in patients with trigeminal neuralgia. J Neurosurg 26 (1 Suppl):159-162, 1967

23. Jannetta PJ: Microsurgery of cranial nerve cross-compression. Clin Neurosurg 26:607-615, 1979

24. Jannetta PJ: Neurovascular compression in cranial nerve and systemic disease. Ann Surg 192:518-525, 1980

25. Jannetta PJ: Observations on the etiology of trigeminal neuralgia, hemifacial spasm, acoustic nerve dysfunction and glossopharyngeal neuralgia. Definitive microsurgical treatment and results in 117 patients. Neurochirurgia (Stuttg) 20:145-154, 1977

26. Kandan SR, Khan S, Jeyaretna DS, Lhatoo S, Patel NK, Coakham HB: Neuralgia of the glossopharyngeal and vagal nerves: long-term outcome following surgical treatment and literature review. Br J Neurosurg 24:441-446, 2010

27. Kanpolat Y, Kahilogullari G, Ugur HC, Elhan AH: Computed tomography-guided percutaneous trigeminal tractotomy-nucleotomy. Neurosurgery 63:ONS147-ONS155, 2008

28. Kanpolat Y, Savas A, Batay F, Sinav A: Computed tomography-guided trigeminal tractotomy-nucleotomy in the management of vagoglossopharyngeal and geniculate neuralgias. Neurosurgery 43:484-490, 1998

29. Katusic S, Williams DB, Beard CM, Bergstralh E, Kurland LT: Incidence and clinical features of glossopharyngeal neuralgia, Rochester, Minnesota, 1945-1984. Neuroepidemiology 10:266-275, 1991

30. Kawashima M, Matsushima T, Inoue T, Mineta T, Masuoka J, Hirakawa N: Microvascular decompression for glossopharyngeal neuralgia through the transcondylar fossa (supracondylar transjugular tubercle) approach. Neurosurgery 66 (6 Suppl Operative):275-280, 2010

31. King J: Glossopharyngeal neuralgia. Clin Exp Neurol 24: 113-121, 1987

32. Kitchener JM: Glossopharyngeal neuralgia responding to pregabalin. Headache 46:1307-1308, 2006 (Erratum in Headache 46:1474, 2006)

33. Kobata H, Kondo A, Iwasaki K, Nishioka T: Combined hyperactive dysfunction syndrome of the cranial nerves: trigeminal neuralgia, hemifacial spasm, and glossopharyngeal neuralgia: 11-year experience and review. Neurosurgery 43:1351-1362, 1998

34. Kondo A: Follow-up results of using microvascular decompression for treatment of glossopharyngeal neuralgia. J Neurosurg 88:221-225, 1998

35. Kong Y, Heyman A, Entman ML, McIntosh HD: Glossopharyngeal neuralgia associated with bradycardia, syncope, and seizures. Circulation 30:109-113, 1964

36. Koopman JSHA, Dieleman JP, Huygen FJ, de Mos M, Martin CGM, Sturkenboom MCJM: Incidence of facial pain in the general population. Pain 147:122-127, 2009

37. Koopman JSHA, Huygen FJ, Dieleman JP, de Mos M, Sturkenboom MCJM: Pharmacological treatment of neuropathic facial pain in the dutch general population. J Pain 11:264272,2010

38. Kunc Z: Treatment of essential neuralgia of the 9th nerve by selective tractotomy. J Neurosurg 23:494-500, 1965

39. Laha RK, Jannetta PJ: Glossopharyngeal neuralgia. J Neurosurg 47:316-320, 1977

40. Lazorthes Y, Verdie JC: Radiofrequency coagulation of the petrous ganglion in glossopharyngeal neuralgia. Neurosurgery 4:512-516, 1979 
41. Love JG: Diagnosis and surgical treatment of glossopharyngeal neuralgia. Surg Clin North Am 24:959-962, 1944

42. Luef G, Poewe W: Oxcarbazepine in glossopharyngeal neuralgia: clinical response and effect on serum lipids. Neurology 63:2447-2448, 2004

43. Mairs AP, Stewart TJ: Surgical treatment of glossopharyngeal neuralgia via the pharyngeal approach. J Laryngol Otol 104:12-16, 1990

44. Manzoni GC, Torelli P: Epidemiology of typical and atypical craniofacial neuralgias. Neurol Sci 26 (Suppl 2):s65-s67, 2005

45. Matsushima T, Goto Y, Natori Y, Matsukado K, Fukui M: Surgical treatment of glossopharyngeal neuralgia as vascular compression syndrome via transcondylar fossa (supracondylar transjugular tubercle) approach. Acta Neurochir (Wien) 142:1359-1363, 2000

46. Michelucci R, Tassinari CA, Samoggia G, Tognetti F, Calbucci F: Intracranial microvascular decompression for "cryptogenic" hemifacial spasm, trigeminal and glossopharyngeal neuralgia, paroxysmal vertigo and tinnitus: II. Clinical study and long-term follow up. Ital J Neurol Sci 7:367-374, 1986

47. Patel A, Kassam A, Horowitz M, Chang YF: Microvascular decompression in the management of glossopharyngeal neuralgia: analysis of 217 cases. Neurosurgery 50:705-711, 2002

48. Pollock BE, Boes CJ: Stereotactic radiosurgery for glossopharyngeal neuralgia: preliminary report of 5 cases. Clinical article. J Neurosurg 115:936-939, 2011

49. Reddy K, Hobson DE, Gomori A, Sutherland GR: Painless glossopharyngeal "neuralgia" with syncope: a case report and literature review. Neurosurgery 21:916-919, 1987

50. Resnick DK, Jannetta PJ, Bissonnette D, Jho HD, Lanzino G: Microvascular decompression for glossopharyngeal neuralgia. Neurosurgery 36:64-69, 1995

51. Ringel RA, Roy EP III: Glossopharyngeal neuralgia: successful treatment with baclofen. Ann Neurol 21:514-515, 1987

52. Robson JT, Bonica J: The vagus nerve in surgical consideration of glossopharyngeal neuralgia. J Neurosurg 7:482-484, 1950

53. Rozen TD: Trigeminal neuralgia and glossopharyngeal neuralgia. Neurol Clin 22:185-206, 2004

54. Rushton JG, Stevens JC, Miller RH: Glossopharyngeal (vagoglossopharyngeal) neuralgia: a study of 217 cases. Arch Neurol 38:201-205, 1981

55. Salar G, Ori C, Baratto V, Iob I, Mingrino S: Selective percutaneous thermolesions of the ninth cranial nerve by lateral cervical approach: report of eight cases. Surg Neurol 20:276-279, 1983

56. Sampson JH, Grossi PM, Asaoka K, Fukushima T: Microvascular decompression for glossopharyngeal neuralgia: longterm effectiveness and complication avoidance. Neurosurgery 54:884-890, 2004

57. Sicard R, Robineau J: Communications et presentations: Part I-algie vélopharyngée essentielle: traitement chirugical. Rev Neurol 36:256-257, 1920

58. St John JN: Glossopharyngeal neuralgia associated with syncope and seizures. Neurosurgery 10:380-383, 1982
59. Stanic S, Franklin SD, Pappas CT, Stern RL: Gamma knife radiosurgery for recurrent glossopharyngeal neuralgia after microvascular decompression. Stereotact Funct Neurosurg 90:188-191, 2012

60. Taha JM, Tew JM: Long-term results of surgical treatment of idiopathic neuralgias of the glossopharyngeal and vagal nerves. Neurosurgery 36:926-931, 1995

61. Taha JM, Tew JM Jr, Keith RW, Payner TD: Intraoperative monitoring of the vagus nerve during intracranial glossopharyngeal and upper vagal rhizotomy: technical note. Neurosurgery 35:775-777, 1994

62. Tarlov IM: Section of the cephalic third of the vagus-spinal accessory complex: clinical and histologic results. Arch Neurol Psychiatry 47:141-148, 1942

63. Thomson JL: Glossopharyngeal neuralgia accompanied by unconsciousness. J Neurosurg 11:511-514, 1954

64. Titlic M, Jukic I, Tonkic A, Grani P, Jukic J: Use of lamotrigine in glossopharyngeal neuralgia: a case report. Headache 46:167-169, 2006

65. Tubbs RS, Mortazavi MM, Loukas M, Shoja MM, CohenGadol AA: Intraoperative and anatomical descriptions of intracranial connections between the glossopharyngeal and vagus nerves: clinical implications. Laboratory investigation. J Neurosurg 115:179-181, 2011

66. Uihlein A, Love JG, Corbin KB: Intracranial section of the glossopharyngeal nerve; sensory changes observed postoperatively. AMA Arch Neurol Psychiatry 74:320-324, 1955

67. Wakiya K, Fukushima T, Miyazaki S: [Results of microvascular decompression in 16 cases of glossopharyngeal neuralgia.] Neurol Med Chir (Tokyo) 29:1113-1118, 1989 (Jpn)

68. Wallin BG, Westerberg CE, Sundlöf G: Syncope induced by glossopharyngeal neuralgia: sympathetic outflow to muscle. Neurology 34:522-524, 1984

69. Xiong NX, Zhao HY, Zhang FC, Liu RE: Vagoglossopharyngeal neuralgia treated by microvascular decompression and glossopharyngeal rhizotomy: clinical results of 21 cases. Stereotact Funct Neurosurg 90:45-50, 2012

70. Yomo S, Arkha Y, Donnet A, Régis J: Gamma Knife surgery for glossopharyngeal neuralgia. Report of 2 cases. J Neurosurg 110:559-563, 2009

71. Yoshioka J, Ueta K, Ohmoto T, Fujiwara T, Tabuchi K: Combined trigeminal and glossopharyngeal neuralgia. Surg Neurol 24:416-420, 1985

Manuscript submitted November 15, 2012.

Accepted December 7, 2012.

Please include this information when citing this paper: DOI: 10.3171/2012.12.FOCUS12391.

Address correspondence to: Aaron A. Cohen-Gadol, M.D., M.Sc., Goodman Campbell Brain and Spine, Indiana University Department of Neurological Surgery, 355 West 16th Street, Suite 5100, Indianapolis, Indiana 46202. email: acohenmd@ gmail.com. 